УДК 616.895:616.891.4:616.89-008.441.41-053.6:364.786

Для цитирования: Коломыцев Д.Ю., Дроздовский Ю.В. Дифференцированные программы реабилитации подростков с пограничными психическими расстройствами и суицидальным поведением. Сибирский вестник психиатрии и наркологии. 2019; 2 (103): 41-46. https://doi.org/10.26617/1810-3111-2019-2(103)-41-46

\title{
Дифференцированные программы реабилитации подростков с погра- ничными психическими расстройствами и суицидальным поведением
}

\section{Коломыцев Д.Ю., Дроздовский Ю.В.}

Омский государственный медицинский университет

Россия, 644001, Омск, ул. Ленина, 12

\section{PEЗЮME}

Совершенствование терапевтических подходов к проблеме суицидального поведения подростков подразумевает исследование модифицируемых факторов риска, к которым, в частности, относятся особенности мышления подростков в рамках переживаемого кризисного состояния. Исследование особенностей кризисного мышления может иметь значение для эффективной психотерапии суицидального поведения, что снижает суицидальный риск в будущем. Целью исследования явилась разработка методов реабилитации и психопрофилактических мероприятий на основе оценки особенностей кризисного мышления подростков с пограничными психическими расстройствами и суицидальным поведением. Результаты. Были исследованы 122 подростка с различными вариантами суицидального поведения, они были разделены на 3 клинические группы: с депрессивным эпизодом $(\mathrm{n}=26)$, с реакциями на стресс и нарушениями адаптации ( $\mathrm{n}=64)$, c формирующимися личностными расстройствами $(\mathrm{n}=32)$. Были изучены клинико-динамические особенности пограничных психических расстройств и суицидального поведения, а также особенности кризисного мышления: когнитивные искажения и метапрограммы сферы суицидогенного конфликта, а также мотивы и личностный смысл суицидального поведения. Суицидальное поведение отличалось своеобразием в клинических группах: было тесно связано с депрессивным синдромом у подростков с депрессивным эпизодом, с острыми психическими травмами по механизмам личностной уязвимости у подростков с реакциями на стресс и нарушениями адаптации, с патохарактерологическим стереотипом реагирования у подростков с формирующимися расстройствами личности. Характеристики кризисного мышления подростков, такие как «эмоциональная отстраненность», «когнитивная слабость», «внимание к недостаткам, цинизм» и «решительность», оказались связанными со степенью тяжести суицидального поведения. В результате были разработаны комплексные дифференцированные программы реабилитации, включающие психофармакологические и психотерапевтические мероприятия, учитывающие когнитивное своеобразие кризисных переживаний подростков, которые показали высокую эффективность в плане снижения суицидального риска.

Ключевые слова: суицидальное поведение, подростки, когнитивные искажения, метапрограммы, пограничные психические расстройства.

\section{ВВЕДЕНИЕ}

Повторное суицидальное поведение является наиболее значимым фактором риска завершенного суицида в будущем [1]. При этом после 17-18 лет суицидальные попытки чаще всего являются повторными [2], что позволяет говорить о формировании стереотипа кризисного реагирования и суицидального поведения в подростковом возрасте, а также остро ставит проблему качественного и наиболее полного оказания помощи подросткам с различными формами суицидального поведения.

Следует отметить, что с целью совершенствования терапевтических подходов к суицидальному поведению наиболее оправданным видится исследование модифицируемых факторов риска [3], к которым относятся, в частности, особенности мышления в рамках пережи- вания кризисного состояния. В связи с тем, что в происхождении суицидального поведения важнейшую роль играет развитие суицидогенного конфликта [4], исследование когнитивной составляющей кризисного реагирования подростков представляется перспективным для понимания динамики суицидального поведения и разработки на этой основе психотерапевтических подходов. Особенности кризисного мышления подростков могут быть рассмотрены как про- и антисуицидальные факторы, поскольку существенно меняют восприятие и переживание суицидогенного конфликта, приводя к различным способам совладания со стрессом [5].

На сегодняшний момент исследователями разработаны различные эффективные лечебнореабилитационные меры, направленные на оказание помощи при суицидальном поведении, 
включающие психофармакологические, психотерапевтические и психосоциальные воздействия [6]. Наиболее целесообразным при этом представляется комплексный и дифференцированный подход, основанный на учете разнообразия клиники суицидального поведения, личностных особенностей суицидента и других факторов [7]. Центральное место в лечебнореабилитационных мероприятиях при суицидальном поведении занимает краткосрочная кризисная психотерапия, разработан и внедрен в практику протокол когнитивно-поведенческой психотерапии суицидального поведения [8, 9]. Современные подходы к кризисной психотерапии также предполагают и полимодальный подход [10]. Существенной задачей психотерапии является не только помощь в рамках преодоления текущего кризиса, но и предотвращение суицидального поведения в будущем [11], что особенно актуально у подростков. Известно, что успешная психотерапия, проводимая в детском и подростковом возрастах, способствует в будущем снижению суицидального риска [12].

\section{ЦЕЛЬ ИССЛЕДОВАНИЯ}

Разработка методов реабилитации и профилактических мероприятий на основе оценки особенностей кризисного мышления подростков с пограничными психическими расстройствами и суицидальным поведением.

\section{МАТЕРИАЛЫ И МЕТОДЫ}

Нами обследовано 122 подростка с пограничными психическими расстройствами, которые были разделены на 3 клинические группы, исходя из предполагаемых механизмов психогенеза суицидального поведения: с депрессивным эпизодом (ДЭ) $(\mathrm{n}=26)$, с реакциями на стресс и нарушениями адаптации (РСНА) (n=64), с формирующими личностными расстройствами (ФЛР) (n=32). Обследованные подростки обнаруживали внутренние и внешние формы суицидального поведения (суицидальные мысли, суицидальные замыслы и намерения, совершенная суицидальная попытка). Подростки с демонстративно-шантажным поведением и намерениями не отделялись от подростков с истинным суицидальным поведением в связи с условностью данных категорий для подростков и наличием кризисных переживаний в обоих случаях.

Основные методы исследования: клиникопсихопатологический, клинико-динамический и методы когнитивно-поведенческой психотерапии и нейролингвистического программирования для исследования когнитивного своеобразия сферы суицидогенного конфликта у подростков.
Полученные данные были обработаны с помощью статистических методов (непараметрические критерии для сравнения связанных и несвязанных выборок, факторный анализ). Bсе приведенные результаты базируются на обнаруженных статистически значимых закономерностях.

\section{РЕЗУЛЬТАТЫ И ИХ ОБСУЖДЕНИЕ}

Нами проведено исследование клиникодинамических закономерностей пограничных психических расстройств у подростков. В результате обнаружено, что для подростков с депрессивным эпизодом существенную роль играли хронические психические травмы, а суицидальное поведение отличалось постепенным развитием и было тесно связано с динамикой депрессивного синдрома. Для подростков с реакциями на стресс и нарушениями адаптации первоочередную роль играли острые психические травмы, которые находили яркое выражение в клинике психических расстройств, а также тесной связи суицидального поведения в первую очередь с характером психической травмы. У большинства подростков данной группы психические расстройства не достигали степени развернутых психопатологических синдромов, при этом суицидальное поведение отличалось относительно быстрым развитием (часы-дни) и отражало срыв адаптационных возможностей личности, в том числе и по механизмам личностной уязвимости, в рамках актуальной психотравмирующей ситуации. Для подростков с формирующимися расстройствами личности была характерна длительная динамика патохарактерологических расстройств с постепенным их становлением под влиянием конституционально-биологических, экзогенноорганических и социально-психологических факторов. Суицидальное поведение у данных подростков в первую очередь было обусловлено патохарактерологическим стереотипом реагирования, носило преимущественно шантажно-демонстративный характер, характеризовалось относительно быстрой динамикой и сопровождалось осознанием собственных мотивов и целей.

Нами были изучены характеристики кризисного мышления подростков: когнитивные искажения и метапрограммы сферы суицидогенного конфликта, а также мотивы и личностный смысл суицидального поведения. Все изученные характеристики кризисного мышления сводились к 8 стратегиям, которые были выделены нами на основании факторного анализа. 
Была обнаружена связь между степенью тяжести суицидального поведения и выраженностью 4 когнитивных стратегий. Когнитивной стратегией, носящей антисуицидальный характер, явилась «эмоциональная отстраненность», которая была связана с возможностью внутренне отстраняться от ситуации, не входить в конфликт, не преувеличивать последствия событий, способностью подростка анализировать мотивы других людей, не вовлекаясь эмоционально в их переживания. Просуицидальной когнитивной стратегией на этапе формирования суицидальных тенденций явилась «когнитивная слабость», которая была связана со склонностью к бездоказательным суждениям, мышлению без оценки контекста ситуации. Просуицидальными когнитивными стратегиями на этапе реализации суицидальных намерений выступали «недостатки, цинизм» (склонность выделять в первую очередь недостатки, сохранять дистанцию с другими людьми со стремлением «читать» их мотивы, построение доводов на основании деталей вне контекста, общие негативные ожидания) и «решительность» (склонность опираться на собственное мнение при принятии решений, наличие в целом оптимистических ожиданий, способность вступать в конфликт).

На основании изученных нами клиникодинамических закономерностей пограничных психических расстройств и суицидального поведения у обследованных подростков, а также особенностей их кризисного мышления были разработаны комплексные дифференцированные программы реабилитации. Выделение особенностей кризисного мышления позволяло дифференцированно использовать психотерапевтические методы, выявлять и обозначать мишени для терапии.

Следует отметить, что при относительно высоком суицидальном риске в рамках комплексной психореабилитации требовалось проведение кризисной психотерапии в соответствии с протоколом когнитивно-поведенческой терапии суицидального поведения вне зависимости от диагноза психического расстройства. По миновании кризисного этапа психотерапевтическое вмешательство было ориентировано на индивидуально-психологическую основу пограничных психических расстройств (психические травмы, внутриличностные конфликты) и на восстановление социальной адаптации, активацию защитно-ресурсного потенциала личности.
Коррекция стратегий кризисного мышления обследованных подростков реализовывалась за счет комплексного применения техник когнитивно-поведенческой психотерапии (коррекция когнитивных искажений, дезадаптивных когнитивных схем и убеждений) и нейролингвистического программирования (расширение динамического диапазона метапрограмм за счет применения широкого ряда технологий). Применение данных методов позволяло влиять на индивидуально-личностные факторы динамики суицидального поведения и психологические факторы патогенеза пограничных психических расстройств. В частности на такую когнитивную стратегию, как «эмоциональная отстраненность», была направлена техника визуально-кинестетической диссоциации при работе с психотравмирующим опытом, а также трехпозиционное восприятие конфликтных ситуаций, на стратегии «когнитивная слабость», «недостатки, цинизм» - работа с когнитивными искажениями и убеждениями методами когнитивно-поведенческой терапии.

Программа реабилитации подростков с депрессивным эпизодом включала в себя назначение антидепрессантов (при тщательном мониторинге суицидального риска) и преимущественно методов когнитивно-поведенческой терапии. Основной мишенью являлась когнитивная депрессивная триада и «автоматические» мысли, связанные с чувством безнадежности. При уменьшении клинических проявлений депрессивного синдрома использовались и психотерапевтические методы, обращенные на дезактуализацию психотравмирующего опыта, разрешение внутриличностных конфликтов. После окончания программы назначалось профилактическое лечение антидепрессантами сроком до 12 месяцев.

Программа реабилитации подростков с реакциями на стресс и нарушениями адаптации подразумевала ведущую роль психотерапии. Основную роль играли методы, направленные на дезактуализацию психических травм, внутриличностных конфликтов, развитие навыков саморегуляции и коммуникации. Психофармакологические средства использовались как вспомогательная мера на кризисном и основном этапах реабилитации, на заключительном этапе происходила их отмена.

Программа реабилитации, разработанная для подростков с формирующимися расстройствами личности, включала назначение патогенетической психофармакотерапии на длитель- 
ный срок в комплексе с психотерапевтическими мероприятиями. Психотерапия преследовала главную цель - изменение когнитивных схем, характерных для того или иного расстройства личности, обучение навыкам саморегуляции, дезактуализацию психотравмирующего опыта.
В отношении всех подростков с актуальным суицидогенным конфликтом в ходе реабилитации была проведена оценка суицидального риска, в том числе с использованием клинического интервью и шкалы безнадежности Бека (Beck Hopelessness Inventory).

Т а б ли ц а 1

Динамика показателей шкалы безнадежности Бека у подростков с пограничными психическими расстройствами и суицидальным поведением

\begin{tabular}{|l|c|c|c|c|}
\hline \multicolumn{1}{|c|}{ Диагноз } & $\begin{array}{l}\text { Шкала безнадежности } \\
\text { Бека (начало терапии) }\end{array}$ & $\begin{array}{l}\text { Бекала безнадежности (конец терапии) } \\
\text { Бекилкоксона, Z }\end{array}$ & $\begin{array}{c}\text { Критерий } \\
\text { Виначость, } \\
\mathrm{p}\end{array}$ \\
\hline Депрессивный эпизод & $13,79 \pm 2,62$ & $7,36 \pm 2,85$ & $-3,829$ & $<0,001$ \\
\hline $\begin{array}{l}\text { Реакции на стресс и наруше- } \\
\text { ния адаптации }\end{array}$ & $9,93 \pm 2,98$ & $5,41 \pm 1,96$ & $-5,721$ & $<0,001$ \\
\hline $\begin{array}{l}\text { Формирующиеся расстройства } \\
\text { личности }\end{array}$ & $9,33 \pm 3,03$ & $7,73 \pm 2,46$ & $-2,379$ & 0,02 \\
\hline
\end{tabular}

В таблице 1 представлена динамика показателей шкалы безнадежности в процессе реабилитации у подростков всех клинических групп. Согласно критерию Вилкоксона для сравнения связанных выборок были обнаружены статистически значимые различия, что говорит об эффективности реабилитации в плане снижения суицидального риска у подростков с пограничными психическими расстройствами и суицидальным поведением.

\section{ЗАКЛЮЧЕНИЕ}

Комплексные реабилитационные мероприятия, разработанные нами на основе клиникопсихопатологического подхода, учитывающие патогенез и динамику пограничных психических расстройств у подростков, а также специфику их кризисного мышления, показали положительные результаты. В ходе проведенного исследования была определена роль стратегий кризисного мышления как фактора динамики суицидального поведения у подростков с пограничными психическими расстройствами в условиях сложного взаимовлияния суицидогенных факторов. На основании полученных результатов могут применяться научно обоснованные дифференцированные меры персонализированной психореабилитации, учитывающие своеобразие кризисного мышления лиц подросткового возраста.

\section{КОНФЛИКТ ИНТЕРЕСОВ}

Авторы заявляют об отсутствии возможных конфликтов интересов в связи с публикацией данной статьи.

\section{ИСТОЧНИК ФИНАНСИРОВАНИЯ}

Авторы подтверждают отсутствие финансирования и спонсорской поддержки при проведении данного исследования.

\section{СООТВЕТСТВИЕ ПРИНЦИПАМ ЭТИКИ}

Работа соответствует этическим стандартам, разработанным в соответствии с Хельсинской декларацией ВМА.

\section{ЛИТЕРАТУРА}

1. Clarke M.C., Coughlan H., Harley M., Connor D, Power E,, Lynch F,, Fitzpatrick C., Cannon M. The impact of adolescent cannabis use, mood disorder and lack of education on attempted suicide in young adulthood. World Psychiatry. 2014; 13 (3): 322-4. Doi: 10. 1002/wps.20170

2. Goldston D.B., Daniel S.S., Erkanli A., Heilbron N., Doyle O., Weller B., Sapyta J. Suicide attempts in a longitudional sample of adolescents followed through adulthood: evidence of escalation. J. Consult. Clin. Psychol. 2015; 83(2): 253-64. http://dx.doi.org/10.1037/a0038657

3. Carter G., Milner A., McGill K., Pirkis J. Predicting suicidal behaviours using clinical instruments: systematic review and meta-analysis of positive predictive values for risk scales. British Journal of Psychiatry. 2017. 210(6): 387-395; https://doi.org/10.1192/bjp.bp.116.182717

4. Амбрумова А.Г., Тихоненко В.А. Диагностика суицидального поведения. Методические рекомендации. М., 1980: 61.

5. Крюкова Т.Л. Когнитивная психология совладания с одиночеством. Вестник Костромского государственного университета. Серия: Педагогика. Психология. Социокинетика. 2013; 19(2): 93-97.

6. Wasserman D., Rihmer Z., Rujesku D., Sarchiapone M., Sokolowski M., Titelman D., Zalsman G., Zemishlany Z., Carli V. The European Psychiatric Association (EPA) guidance on suicidal treatment and prevention. European Psychiatry. 2012. 27(2): 129141. DOI: 10.1016/j.eurpsy.2011.06.003

7. Положий Б.С., Панченко Е.А., Григорьева М.В. Дифференцированные подходы к психотерапии 
лиц, совершивших покушение на самоубийство. Психическое здоровье. 2014; 7: 32-36.

8. Wenzel A., Jager-Hyman S. Cognitive Therapy for Suicidal Patients: Current Status. The Behavior Therapist. 2012; 35(7): 121-130.

9. Wenzel A., Brown G.K., Beck A.T. Cognitive therapy for suicidal patients: Scientific and clinical applications. Washington: American Psychological Association, 2009: 377.

10. Меринов А.В., Федотов И.А., Куликов С.О. Сравнение методов психотерапевтического лечения аутоагрессивного поведения (обзор литературы). Академический журнал Западной Сибири. 2015; 11, 2(57): 128-132.
11. Холмогорова А.Б. Суицидальное поведение: теоретическая модель и практика помощи в когнитивно-бихевиоральной терапии. Консультативная психология и психотерапия. 2016; 24 (3): 144-163. Doi: 10.17759/cpp.20162403009

12. Wolk C.B., Kendall Ph.C., Beidas R.C. Cognitivebehavioral therapy for child anxiety confers longterm protection from suicidality. Journal of the American Academy of Child \& Adolescent Psychiatry. 2015; 54(3): 175-179. DOI: http://dx.doi.org/10.1016/j.jaac.2014.12.004

Поступила в редакцию 04.02.2019 Утверждена к печати 8.04.2019

Коломыцев Дмитрий Юрьевич - ассистент кафедры психиатрии, медицинской психологии ФГБОУ ВО «Омский государственный медицинский университет» Минздрава РФ (SPIN-код: 2454-7852. Researcher ID: Q7409-2018. ORCID iD: 0000-0002-9330-4438)

Дроздовский Юрий Викентьевич - профессор, доктор медицинских наук; заведующий кафедрой психиатрии, медицинской психологии ФГБОУ ВО «Омский государственный медицинский университет» Минздрава РФ.

Коломыцев Дмитрий Юрьевич, d.kolomytsev@icloud.com

Дроздовский Юрий Викентьевич, jwdrozd@mail.ru

УДК 616.895:616.891.4:616.89-008.441.41-053.6:364.786

For citation: Kolomytsev D.Yu., Drozdovsky Yu.V. Differentiated rehabilitation programs for adolescents with borderline mental disorders and suicidal behavior. Siberian Herald of Psychiatry and Addiction Psychiatry. 2019; 2 (103): 41-46. https://doi.org/10.26617/1810-3111-2019-2(103)-41-46

\section{Differentiated rehabilitation programs for adolescents with borderline mental disorders and suicidal behavior}

\section{Kolomytsev D.Yu., Drozdovsky Yu.V.}

Omsk State Medical University

Lenin Street 12, 644001, Omsk, Russian Federation

\section{ABSTRACT}

Improving therapeutic approaches to the problem of suicidal behavior of adolescents involves the study of modifiable risk factors, which include, in particular, the specificity of adolescent thinking in crisis state. Investigating the characteristics of crisis thinking may be important for effective psychotherapy of suicidal behavior, which reduces suicidal risk in the future. The aim of the study was to develop methods of rehabilitation and preventive measures based on an assessment of the characteristics of crisis thinking of adolescents with borderline mental disorders and suicidal behavior. 122 adolescents with various suicidal behaviors were studied, they were divided into 3 clinical groups: with a depressive episode $(n=26)$, with stress reactions and adjustment disorders $(n=64)$, with emerging personality disorders $(n=32)$. The clinical and dynamic features of borderline disorders and suicidal behavior were studied, as well as features of crisis thinking: cognitive distortions and meta-programs of suicidal conflict, as well as motives and personal meaning of suicidal behavior. Suicidal behavior was specific in clinical groups: it was closely associated with depressive syndrome in adolescents with a depressive episode, with acute mental trauma according to the mechanisms of personality vulnerability in adolescents with stress reactions and adjustment disorders, with a pathocharacterological stereotype of response in adolescents with emerging personality disorders. Characteristics of adolescent crisis thinking such as "emotional resignation," "cognitive weakness," "attention to shortcomings, cynicism," and "decisiveness" turned out to be related to the severity of suicidal behavior. As a result, complex differentiated rehabilitation programs were developed, including psychopharmacological and psychotherapeutic measures that took into account the cognitive identity of crisis experiences of adolescents, which had shown high efficacy in reducing suicidal risk.

Keywords: suicidal behavior, adolescents, cognitive distortions, meta-programs, borderline mental disorders. 


\section{REFERENCES}

1. Clarke M.C., Coughlan H., Harley M., Connor D, Power E,, Lynch F,, Fitzpatrick C., Cannon M. The impact of adolescent cannabis use, mood disorder and lack of education on attempted suicide in young adulthood. World Psychiatry. 2014; 13 (3): 322-4. Doi: 10. 1002/wps.20170

2. Goldston D.B., Daniel S.S., Erkanli A., Heilbron N., Doyle O., Weller B., Sapyta J. Suicide attempts in a longitudinal sample of adolescents followed through adulthood: evidence of escalation. J. Consult. Clin. Psychol. 2015; 83(2): 253-64. http://dx.doi.org/10.1037/a0038657

3. Carter G., Milner A., McGill K., Pirkis J. Predicting suicidal behaviours using clinical instruments: systematic review and meta-analysis of positive predictive values for risk scales. British Journal of Psychiatry. 2017. 210(6): 387-395; https://doi.org/10.1192/bjp.bp.116.182717

4. Ambrumova A.G., Tikhonenko V.A. Diagnostika suicidal'nogo povedenija. Metodicheskie rekomendacii [Diagnosis of suicidal behavior. Methodical recommendation]. Moscow, 1980: 61 (in Russian).

5. Kryukova T.L. Kognitivnaja psihologija sovladanija s odinochestvom [Cognitive psychology of coping with loneliness]. Vestnik Kostromskogo gosudarstvennogo univesiteta. Serija: Pedagogika. Psihologija. Sociokinetika - Bulletin of Kostroma State University. Series: Pedagogy. Psychology. Sociogenetics. 2013; 19(2): 93-97 (in Russian).

6. Wasserman D., Rihmer Z., Rujesku D., Sarchiapone M., Sokolowski M., Titelman D., Zalsman G., Zemishlany Z., Carli V. The European Psychiatric Association (EPA) guidance on suicidal treatment and prevention. European Psychiatry. 2012. 27(2): 129141. DOI: 10.1016/j.eurpsy.2011.06.003
7. Polozhy B.S., Panchenko E.A., Grigorieva M.V. Differencirovannye podhody $\mathrm{k}$ psihoterapii lic, sovershivshih pokushenie na samoubijstvo [Differentiated approaches to psychotherapy of persons who attempted suicide]. Psihicheskoe zdorov'e Mental Health. 2014; 7: 32-36 (in Russian).

8. Wenzel A., Jager-Hyman S. Cognitive Therapy for Suicidal Patients: Current Status. The Behavior Therapist. 2012; 35(7): 121-130.

9. Wenzel A., Brown G.K., Beck A.T. Cognitive therapy for suicidal patients: Scientific and clinical applications. Washington: American Psychological Association, 2009: 377.

10. Merinov A.V., Fedotov I.A., Kulikov S.O. Sravnenie metodov psihoterapevticheskogo lechenija autoagressivnogo povedenija (obzor literatury). [Comparison of methods of psychotherapeutic treatment of self-injurious behavior (literature review)]. Akademicheskij zhurnal Zapadnoj Sibiri.. Academic Journal of Western Siberia. 2015; 11, 2(57): 128-132 (in Russian).

11. Kholmogorova A.B. Suicidal'noe povedenie: teoreticheskaja model' i praktika pomoshhi v kognitivnobihevioral'noj terapii [Suicidal behavior: theoretical model and practice of assistance in cognitivebehavioral therapy]. Konsul'tativnaja psihologija $i$ psihoterapija - Counseling Psychology and Psychotherapy. 2016; 24 (3): 144-163 (in Russian). Doi: 10.17759/cpp.20162403009

12. Wolk C.B., Kendall Ph.C., Beidas R.C. Cognitivebehavioral therapy for child anxiety confers longterm protection from suicidality. Journal of the American Academy of Child \& Adolescent Psychiatry. 2015; 54(3): 175-179. DOI: http://dx.doi.org/10.1016/j.jaac.2014.12.004

Received February 04.2019 Accepted April 08.2019

Kolomytsev Dmitry Yu. - Assistant of the Department of Psychiatry, Medical Psychology, Omsk State Medical University of the Ministry of Health of the Russian Federation (SPIN-code: 2454-7852. Researcher ID: Q-7409-2018. ORCID iD: 0000-0002-9330-4438)

Drozdovsky Yury V. - Prof. MD, Head of the Department of Psychiatry, Medical Psychology, Omsk State Medical University of the Ministry of Health of the Russian Federation

Kolomytsev Dmitry Yu., d.kolomytsev@icloud.com

Drozdovsky Yury V., jwdrozd@mail.ru 